\title{
“O QUE É A ENFERMAGEM?": CONCEPÇÕES DE ACADÊMICOS DE ENFERMAGEM SOBRE O QUE SIGNIFICA SER ENFERMEIRO*
}

\author{
Ana Cláudia Souza Pereira- Enfermeira da Secretaria Municipal de Saúde Jataí-GO. \\ anita.claudia@gmail.com \\ Isabella Cristina Lima dos Prazeres- Enfermeira do Centro de Uro Nefrologia Jataí-GO \\ belaisa16@hotmail.com \\ Wender Lopes Rezende- Enfermeiro da Secretaria Municipal de Saúde Jataí- GO \\ wenderenf@gmail.com \\ Luiz Almeida Silva - Docente da Universidade Federal de Goiás- Regional Jataí \\ enferluiz@yahoo.com.br \\ Valquíria Coelho Pina Paulino- Docente da Universidade Federal de Goiás- Regional Jataí \\ valquiria.enf.ufg@gmail.com
}

\begin{abstract}
RESUMO: Trata-se de um estudo descritivo de abordagem qualitativa, que se propõe a analisar as concepções de acadêmicos de enfermagem de uma universidade pública do sudoeste goiano sobre a Enfermagem e o que representa ser enfermeiro. Os sujeitos da pesquisa foram dezoito acadêmicos do segundo e décimo período, constituindo os ingressos e a primeira turma de egressos do curso. Os dados foram analisados à luz da análise de conteúdo de Bardin, modalidade temática. A partir das respostas às questões discursivas, emergiram três grandes categorias: paradigma médico biológico; repercussões da História da Enfermagem e Enfermagem: ciência do cuidado. A análise dos discursos possibilitou identificar concepções que se referem à enfermagem enquanto arte, vocação, doação, cuidado e ciência. Ao comparar as concepções entre os períodos, observamos que alunos que representam os egressos do curso, possuem uma visão mais ampla da enfermagem, abarcada de valores e atributos científicos, herança do contínuo processo ensino aprendizagem.
\end{abstract}

Palavras-chave: Enfermagem. Estudantes de Enfermagem. Educação em Enfermagem. História da Enfermagem.

ABSTRACT: This paper presents a descriptive study in a qualitative approach. It also aims to analyse the student nurse's opinion in a public university located at the Goiás' Southwest Brazil- about Nursing and what the related profession represents. The individuals of the research were eighteen students from the second and the last term, among those ones who entered the Nursing College, and the first graduated class of the course. The data were verified with the enlightenment of Bardain's Content Analysis (subject type). As of the answers to the writing questions, three huge categories raised: biological medical's paradigm, Nursing History's Backlashes and Nursing: the science of the care. The discourse's verification made the opinion's identification about Nursing as art, calling, donation, care and science. Comparing the points of view between the terms, we could notice that graduated have a more accurate belief about Nursing that reaches values and scientific attributes as a result of the non stop teaching-learning process.

Keywords: Nursing. Students Nursing. Nursing Education. Nursing History.

\footnotetext{
${ }^{*}$ Pesquisa aprovada pelo Comitê de Ética e Pesquisa da Universidade Federal de Goiás sob o Protocolo nº. 143/12.
} 


\section{INTRODUÇÃO}

O enfermeiro é definido pelas Diretrizes Curriculares Nacionais como profissional qualificado para o exercício de Enfermagem, com base no rigor científico e intelectual e pautado em princípios éticos. Este profissional deve ser capaz de atuar, com senso de responsabilidade social e compromisso com a cidadania, como promotor da saúde integral do ser humano (BRASIL, 2001).

Para isso, é necessário que durante a graduação, os acadêmicos de enfermagem tenham o conhecimento sobre o seu papel social enquanto enfermeiros, que sejam preparados para que tenham condições de exercer a sua profissão como é preconizado pelas diretrizes curriculares. Assim as universidades, os docentes, têm um papel preponderante, uma vez que são agentes do processo educativo, facilitadores do processo de formação e podem efetivamente estimular as mudanças necessárias (BRASIL, 2007). No mesmo sentido os alunos, enquanto sujeitos do processo devem buscar de forma ativa construir-se ao longo do curso, descobrir o seu papel social enquanto futuro enfermeiro preocupar-se com a sua formação, romper com as dificuldades que limitam este processo e conhecer as perspectivas deste novo contex to de saúde.

Nesse tocante, a realização de estudos acerca das concepções de acadêmicos e de egressos sobre o papel do enfermeiro pode melhorar a qualidade do ensino de enfermagem, servindo de parâmetros para reflexão sobre a realidade. Assim sendo, conhecer o que pensam esses sujeitos é de suma importância quando se quer discutir o processo de formação em enfermagem (CARRIJO, et al., 2007; BRANQUINHO, et al., 2011).

Assim, considera-se necessário discutir como os discentes do curso de enfermagem de uma Universidade Federal do sudoeste goiano, concebem sua futura profissão partindo de experiências e conhecimentos que a graduação proporciona. Neste sentido, o interesse pela temática surgiu em nossa prática acadêmica, mediante observações empíricas, ocorridas durante discussões em aulas teóricas e eventos acadêmicos, onde pudemos perceber nos discursos dos discentes, dificuldades em conceber a dimensão do papel do enfermeiro no atual contexto de saúde.

Neste sentido, esse estudo torna-se relevante na medida em que permitirá analisar e discutir as concepções de enfermeirandos acerca da enfermagem e do seu papel, avaliando de maneira crítica e reflexiva o impacto da formação na construção e desconstrução de ideias, podendo acarretar em possíveis interferências nesse processo. Dessa forma, são objetivos deste estudo analisar as concepções de ingressos e egressos do curso de graduação em enfermagem 
da Universidade Federal de Goiás - Campus Jataí, sobre o que é a enfermagem e o que significa/representa ser enfermeiro.

\section{CAMINHO METODOLÓGICO}

Trata-se de um estudo descritivo de abordagem qualitativa, pela qual se propõe observar, conhecer, descrever e interpretar de maneira crítica as concepções dos acadêmicos acerca da Enfermagem e do ser enfermeiro.

A pesquisa foi realizada no Curso de Enfermagem da Universidade Federal de Goiás Campus Jataí, localizada no sudoeste goiano. Os sujeitos da pesquisa foram acadêmicos do $2^{\circ}$ e $10^{\circ}$ período, constituindo os ingressos e a primeira turma de egressos do curso. Os critérios de inclusão foram: ter idade $\geq 18$ anos; estar regularmente matriculado no curso de Enfermagem da referida Universidade; aceitar participar voluntariamente da pesquisa e assinar o termo de consentimento livre e esclarecido (TCLE).

A coleta de dados foi realizada nos meses de novembro de 2012 e janeiro de 2013 . O convite para participar do estudo se deu em horários correspondentes ao termino de aulas das duas turmas, em dias e horários pré-agendados. Na ocasião apresentamos o projeto de pesquisa, objetivos e procedimentos da coleta, após anuência dos sujeitos e assinatura do Termo de Consentimento foi aplicado um questionário, respondido na presença de um dos pesquisadores, no ambiente de sala de aula.

Foi aplicado um questionário semiestruturado contendo questões fechadas a respeito do perfil dos sujeitos, e perguntas abertas que permitiram ao sujeito responder livremente usando sua própria linguagem, demonstrando assim, suas crenças e concepções sobre os fenômenos investigados. O referido questionário continha seis questões que contemplavam as concepções dos acadêmicos sobre a Enfermagem, sobre o ser enfermeiro, papel do enfermeiro nos serviços de saúde e perspectivas dos enfermeirandos quanto ao seu futuro profissional.

Nesse estudo analisamos as três questões referentes às concepções sobre a Enfermagem e ser enfermeiro, a saber: 1- Qual a sua concepção sobre a enfermagem quando você ingressou no curso? 2- Na sua concepção o que é Enfermagem? O que significa/representa ser enfermeiro? 3- Em sua opinião quais as características necessárias para ser um bom enfermeiro?.

O projeto de pesquisa cumpriu as determinações éticas descritas nas normas da Resolução nº196, de 10 de outubro de 1996, sendo, aprovado pelo Comitê de Ética e Pesquisa da Universidade Federal de Goiás sob o Protocolo nº ${ }^{\circ}$ 143/12. 
Os dados foram analisados à luz da análise de conteúdo de Bardin, modalidade temática (BARDIN, 2011). Procedemos com a pré-análise por meio da leitura flutuante; formulação das hipóteses e objetivos da análise; referenciação dos núcleos de sentido; codificação, na qual foram feitos recortes e categorização. O tratamento dos resultados e interpretação constituiu a última fase do tratamento dos dados, a análise propriamente dita.

\section{APRESENTAÇÃO E ANÁLISE DOS DADOS}

Foram sujeitos da pesquisa dezoito acadêmicos do segundo e décimo período, sendo, onze e sete indivíduos respectivamente. O gênero predominante é o feminino, correspondendo a 16 sujeitos $(88,9 \%)$, já o masculino é representado por dois indivíduos $(11,1 \%)$; a média de idade encontrada é a de 22,3 anos, sendo, a menor idade 18 anos e a maior, 27 anos. Em relação ao estado civil, dois indivíduos são casados $(11,1 \%)$, os demais, solteiros.

Os sujeitos de ambos os períodos foram identificados por codinomes, garantindo assim, a confidencialidade da pesquisa. Os codinomes escolhidos são figuras e personagens da mitologia grega. Salientamos que o gênero das personagens e figuras mitológicas não representa necessariamente o gênero dos sujeitos.

A análise das respostas às questões discursivas culminou na identificação de núcleos temáticos de onde emergiram três grandes categorias: paradigma médico biológico; repercussões da história da enfermagem e enfermagem: ciência do cuidado.

\section{Paradigma médico biológico}

Ao realizar uma retrospectiva histórica da enfermagem brasileira percebe-se que o caráter hospitalocêntrico tem origem na criação da escola de enfermagem Anna Nery no ano de 1923, onde o ensino sistematizado tinha como finalidade formar profissionais que garantissem o saneamento urbano, condição necessária à continuidade do comércio internacional, que se encontrava ameaçado pelas epidemias (GALLEGUILLOS, et al., 2001). Em 1931 a Escola de Enfermagem Anna Nery foi elevada ao título de escola padrão por força de Lei Decreto 20.109 de 15/06/31, configurando-a como modelo para as outras que existiam ou que viessem a surgir (GABRIELLI, 2004). O modelo adotado reproduzia “[...] de forma hegemônica o currículo norte-americano, direcionado para o trabalho de enfermagem em instituições hospitalares, atendendo à medicina curativa e hospitalar" (GALLEGUILLOS, et al., 2001, p. 81).

Com a educação em Enfermagem já solidificada, pela sua integração aos programas universitários e governamentais, passamos a ter uma formação limitada basicamente à 
assistência hospitalar, juntamente, observa-se um crescimento quantitativo das demais categorias na Enfermagem, para suprir às novas exigências do mercado de trabalho (GEOVANINI, et al, 2010).

No final da década de 60 por conta da Reforma Universitária “apregoa-se a ampliação do número de vagas e a modernização do Ensino Superior, além da consequente necessidade de revisão dos currículos mínimos dos cursos" (HADDAD, et al., 2006, p. 144). Com aumento dos cursos de graduação e pós graduação, com a sofisticação da tecnologia hospitalar e a constante especialização da medicina, os currículos dos cursos de Enfermagem, foram centrados na assistência curativa e hospitalocêntrica, onde grande parte da carga horária era destinada as disciplinas biomédicas e curativas e ao estágio hospitalar (GEOVANINI, et al., 2010).

Nesse sentido, ao analisarmos os discursos de alguns alunos deste estudo sobre as suas concepções de enfermagem ao ingressarem na graduação, percebe-se que esse modelo ainda se encontra presente nas representações que se fazem sobre o profissional de enfermagem no Brasil, como pode ser verificado nos discursos que se seguem:

“(...) o enfermeiro é aquele que trabalha somente em hospitais sobre ordem de um médico”. (Orestes)

"Achava que era só cuidar de um doente mas agora percebo que é bem mais que isso”. (Poseidon)

No discurso do primeiro sujeito, percebe-se que o enfermeiro pode ser identificado como um profissional que tem função essencialmente hospitalar, como executor da terapêutica prescrita por um médico. Em relação ao segundo sujeito observa-se que ele desconhecia os campos de atuação do enfermeiro, acreditando que este profissional só atua quando a doença está instalada. Além disso, as falas demonstram que os sujeitos apresentavam uma percepção restrita sobre o que é ser enfermeiro, deixando de mencionar outras atribuições desse profissional como, por exemplo: promoção, proteção e recuperação da saúde, além do caráter administrativo e gerencial que são realizados por este profissional.

Um estudo realizado sobre a imagem do enfermeiro com alunos do ensino médio de uma escola particular de Londrina corroboram com as representações observadas nas falas dos sujeitos ingressantes envolvidos nesta pesquisa. Os resultados indicaram representações de pouca valorização, onde o enfermeiro é visto como auxiliar do médico e submisso, mero cumpridor de ordens; demonstrou ainda, desconhecimento da formação educacional e dos campos e possibilidades de atuação, relacionando a imagem da profissão exclusivamente ao 
ambiente hospitalar. Esses alunos demonstraram desconhecimento da autonomia profissional do enfermeiro (KEMMER, et al., 2007).

A relação entre estes estudos demonstram como algumas visões sobre o ser enfermeiro no Brasil ainda estão associadas a concepções clássicas da profissão construídas e difundidas no início do século XX. Como se vê essas concepções são reproduzidas pela sociedade e acompanham alguns alunos até o inicio do curso de graduação em enfermagem. Contudo é possível inferir também que o curso pode contribuir para a desconstrução dessa imagem sobre a profissão, uma vez que a mesma pergunta respondida pelos(as) alunos(as) que estão concluindo o curso de enfermagem não apresentam respostas que restringiam a enfermagem ao modelo hospitalocêntrico.

\section{Repercussões da História da enfermagem}

$\mathrm{Na}$ presente categoria agrupamos as respostas dos sujeitos que possuem núcleo de sentido com gênese na História do cuidado e da profissão, são conteúdos que revelam uma íntima relação com os valores, códigos e crenças perpassadas ao longo dos tempos e que estão descritos nos registros da história da Enfermagem e na conduta, ação-reflexão de seus representantes.

\section{Concepção sobre a enfermagem ao ingressar no curso}

A respeito da concepção que tinham ao ingressar no curso, os sujeitos revelam:

"Não tinha nenhuma concepção formada sobre a enfermagem, sabia apenas que a enfermeira padrão exercia a função de gerencia e cuidado”. (Apolo)

"Não sabia o que significava a profissão na verdade em sua totalidade, tinha uma noção do que vi do trabalho de enfermeiro em minhas vivencias mas não tinha ideia as missão responsabilidade e importância desse profissional”. (Dionísio)

O conteúdo das falas de Apolo e Dionísio revela um desconhecimento sobre a profissão ao ingressarem no curso, o que pode ser explicado pela confusão que se faz no imaginário social sobre o real papel do enfermeiro. Dificilmente o ofício da enfermagem é apresentado e vendido pela mídia com base na realidade profissional, ao contrário, na maioria das vezes se menciona a enfermagem de maneira pejorativa e carregada de estereótipos, atribuindo à profissão um caráter de ajuda e submissão ao saber médico. Em um estudo reflexivo a respeito do ataque da mídia à imagem corporal da enfermeira, Colpo, et al. (2006, 
p.68) destaca que "cada vez mais a mídia tem influenciado decisões, interfere inarbitrariamente na formação de opiniões, põe em choque culturas e estereotipa pessoas e profissões".

Durante muito tempo a Igreja assumia a liderança na assistência do cuidado, é aí que surge a instituição hospitalar, e, deste modo a enfermagem passa a ser executada, em grande maioria por religiosos (KAWAMOTO, 1997).

Entretanto, por conta das reformas protestantes, promovidas por Lutero, Henrique VIII e Calvino (na Alemanha, Inglaterra e Suíça respectivamente) no século XVI, houve um período conhecido como crítico, negro ou período de decadência da enfermagem. Nesse período, inúmeros hospitais foram fechados e as religiosas expulsas em renuncia ao catolicismo. Decaiu a assistência aos doentes e até mesmo os mais simples cuidados como os banhos aos doentes tornaram-se raros (PAIXÃO, 1979; PEREIRA, 2008; GEOVANINI, et al., 2010). Como resultado desses movimentos muitos hospitais tiveram que contratar mão-de-obra desqualificada e com baixa remuneração, mulheres de baixo nível moral e social assumiam o cuidado, deixando os enfermos a mercê da própria sorte (PAIXÃO, 1979; GENTIL, 2009).

Por conta das mudanças ocorridas nesse período perdem-se valores religiosos que abarcavam o cuidado até esse período, a imagem sagrado-cristão que se concebia da enfermagem, dá lugar ao profano, ao negro e ao corrompido, a identidade profissional passa a ser negativa aos olhos de uma sociedade, bastante conservadora. Entretanto, a enfermagem moderna começa a se desenvolver no século XIX, por meio de Florence Nightingale, com base no rigor técnico e científico. Ao criar a primeira escola de enfermagem profissional, Nightingale tinha o propósito de:

[...] afastar a imagem das enfermeiras leigas, preocupando-se principalmente com a origem socio-econômica e conduta moral das alunas e em estabelecer a imagem da enfermeira como anjo branco, abnegada, submissa, intocável e sagrado-cristã (GENTIL, 2009, p. 917).

No discurso de Hera, Pegaso e Hércules, encontramos alguns valores que eram apregoados por Florence:

\section{“[...] alguém que ajuda a salvar vidas”. (Hera) \\ "[...] uma profissão muito difícil, que só quem ama muito é que permanece”. (Pegaso) \\ "Havia uma visual (visão) superficial de um ser cuidador, alguém que se dedicava pelo outro”. (Hércules)}

As concepções de Enfermagem para os sujeitos, como amor, devoção, ajuda, serviço e anjo de branco (aquele que salva vidas) estão ligados com os atributos herdados dos princípios 
da escola nightingaleana e do espírito e preceitos cristãos que sempre permearam o cuidado e que foram transferidos ao longo dos séculos subjetivamente ou de forma objetiva por meio do ensino, sobre isso Germano (1993), enfatiza:

O sentimento de religiosidade entre os primeiros a exercerem a enfermagem muito marcou seu espírito até hoje, haja vista todo um discurso ideológico difundido por escolas, serviços e pela própria Revista brasileira de enfermagem sobre as qualidades inerentes ao bom profissional, aparecem como características de primeira ordem, a obediência, o respeito à hierarquia, a humildade, o espírito de servir, dentre outras (GERMANO, 1993, p. 24).

Para a autora, a ideologia da enfermagem desde os primórdios da profissão significa: "abnegação, obediência, disciplina, dedicação" (p.25). Essa herança ideológica trouxe inúmeras repercussões para a enfermagem, dentre elas o fato de enfermeiros enfrentarem sérias dificuldades profissionais, como as longas jornadas de trabalho e os baixos salários. A autora acredita que a formação acadêmica por desempenhar um importante papel na formação do enfermeiro, tem reforçado toda essa ideologia.

\section{Enfermagem e representações sobre o significado de ser enfermeiro}

Ainda sobre os valores da escola nightingaleana, os sujeitos quando questionados: "Na sua concepção o que é Enfermagem? O que significa/representa ser enfermeiro?" evidenciaram os seguintes discursos:

“[...] Ser enfermeiro é ter paciência, pois você vai lidar com pessoas, e isso não é fácil, é saber ouvir...”. (Ares)

"Enfermagem é desde planejar o cuidado com o outro até mesmo exercer este cuidado com ética e perfeição”. (Poseidon)

"É dar o melhor de si, é estar perto de alguém na hora da dor é ser um anjo para algumas pessoas”. (Atenas)

“[...] uma missão que pode melhorar e salvar vidas”. (Dionísio)

"[...] é doar-se incondicionalmente ao próximo, nos momentos do nascimento até a morte”. (Perseu)

"[...] é tentar ajudar de algum modo, sem distinção, com muita responsabilidade [...]”. (Pegaso)

"[...] Enfermagem é cuidar. Ser enfermeiro é prestar cuidado, gerenciar o cuidado, se colocar a disposição do outro [...]”. (Medusa) 
Como podemos observar no conteúdo dessas falas, grande parte dos sujeitos, de ambos os períodos, possuem uma concepção de Enfermagem permeada de valores religiosos, difundidos por Nightingale e pelas primeiras escolas de enfermagem no Brasil, que na ocasião, seguiam o modelo de ensino adotado por Florence na Europa.

A concepção de ajuda, serviço, doação e caráter caritativo estão presentes nas falas de todos os sujeitos, entretanto, a ideia difundida por Nightingale de que o enfermeiro necessita ser um anjo de branco, puro, sagrado-cristão e abnegado, exercendo sua atividade com perfeição enquanto vocação, missão divina, está explicito no discurso de Poseidon, Atenas e Dionísio, o que nos leva a refletir que tais repercussões históricas vigoram até hoje no imaginário dos indivíduos.

A respeito disso, um estudo observou entre um grupo de enfermeirandos que a visão da profissão antes da graduação era a de Enfermagem enquanto "ajuda, dedicação, devoção e submissão, não compatível com o intenso desejo de ter uma profissão, que impõe respeito" (SOUZA JÚNIOR, et al., 2003, p.455). Essa concepção de enfermagem enquanto vocação e do enfermeiro enquanto pessoa benevolente e abnegada não é compatível com a prática profissional do enfermeiro, pois o mesmo "precisa vender a sua força de trabalho para garantir a sua existência" (RODRIGUES, 2001).

A formação acadêmica exerce um papel importante na construção e mudança das concepções dos sujeitos, devendo, o quanto antes aproximá-los da realidade de sua prática profissional (ROSA, et al., 2005). Essas autoras realizaram um estudo entre estudantes de diferentes períodos da Escola de Enfermagem da UFRGS, sendo 29 acadêmicos do primeiro semestre, 18 do quinto e 34 do nono. O estudo revelou uma diferença nos discursos dos três grupos de alunos. Os alunos do primeiro semestre referem-se a enfermagem como vocação, já os do nono semestre expressam concepções ligadas a prática da enfermagem enquanto profissão e ciência do cuidar, não atribuindo ao enfermeiro o caráter caritativo e abnegado que o outro extremo expressou.

Entretanto, em nosso estudo verifica-se pelo conteúdo das falas que essa concepção religiosa está presente entre alguns indivíduos do último período, porém, permeado a um discurso científico, apresentando a enfermagem como ciência do cuidado e prática vocacional, reforçando valores religiosos difundidos por Florence.

Para que ocorram mudanças quanto à visibilidade profissional é necessário que os cursos de formação, os enfermeirandos e os enfermeiros assumam papel de defesa da profissão, fazendo seu "marketing pessoal" (KEMMER, et al., 2007; ERDMANN, et al., 2009; GENTIL, 2009; BAGGIO, et al., 2010). 
Os enfermeiros recém formados devem conhecer seu papel e interpretá-lo para os demais, caso contrário corre-se o risco de vivenciar situações estressantes que contribuem para a insatisfação profissional (SOUZA JÚNIOR, et al., 2003) e desvalorização social da profissão. O conteúdo da fala de alguns sujeitos revela uma concepção de enfermagem enquanto vocação e arte:

\author{
"É a arte de cuidar do próximo [...]". (Zeus) \\ "Enfermagem é a arte do cuidar de pessoas [...]". (Afrodite) \\ "Enfermagem é a arte de cuidar do próximo, de forma holística, respeitando \\ seus limites". (Perseu)
}

Florence foi responsável por difundir a ideia de predisposição feminina ao cuidado e atenção à saúde, por acreditar que a enfermagem era um dom, uma arte e vocação feminina (WAINBERG, 2004; LANZA, 2006).

Refletir sobre a arte na enfermagem é refletir sobre as questões de gênero, pois, acreditamos que essa concepção está atravessada subjetivamente de conceitos herdados na concepção de instinto e feminilidade. Nessa concepção a mulher seria a detentora instintiva das artes, pois, ela estaria naturalmente preparada para o cuidar, esta ideia reforça aspectos do cuidado que são intrínsecos da natureza feminina e que contribuem para o distanciamento da figura masculina na profissão.

Acreditamos que o discurso de enfermagem enquanto arte ao ser difundido por Florence na Europa e pela Escola de Enfermagem Anna Nery no Brasil, influenciou a formação da identidade profissional da enfermagem brasileira, ao passo que o modelo de ensino obedecia o padrão nightingaleano. Ao adotar esse modelo as Escolas de Enfermagem no Brasil passam os princípios de: submissão, espírito de serviço, obediência, disciplina e abnegação (GEOVANINI, et al., 2010).

Neste estudo não buscamos a desconstrução da arte do cuidar, mas, fazemos uma crítica à repercussão histórica desse discurso, que por muito tempo contribuiu de maneira negativa para enfermagem, onde se priorizou valores caritativos e religiosos em detrimento à ciência. Por outro lado, não defendemos a enfermagem somente enquanto ciência do cuidado, mas como ciência e arte, arte no sentido estético, produto final da atividade humana, unindo conhecimento técnico e emoção, que remete ao cuidado humano e não à doença ou ao corpo doente; à ciência holística, à humanização, à ética, dedicação e busca de qualidade no cuidado. 
A esse respeito compartilhamos a descrição do padrão de conhecimento estético de Cestari (2003, p.37):

O padrão estético corresponde à arte da enfermagem que é expressiva, subjetiva, e se torna visível na ação de cuidar. [...] A arte está relacionada à prática profissional, ou seja a arte é expressa no processo de interação entre enfermeira e cliente, despertando a capacidade do cliente de enfrentar desafios. [...] O cuidado humano é uma postura ética e estética frente ao mundo e exige a 'conjugação do conhecimento, habilidades manuais, da intuição, da experiência e da expressão da sensibilidade'. A forma como o conhecimento, o julgamento e a habilidade são utilizadas na área clínica é o fenômeno que, geralmente, é denominado de arte da enfermagem. Nos trabalhos de estudiosos da enfermagem, podem ser identificadas cinco concepções de arte: compreender o significado no encontro com o paciente; estabelecer conexão significativa com o paciente; realizar uma atividade de enfermagem engenhosa; determinar um curso apropriado para a ação de enfermagem; adotar uma conduta ética na prática de enfermagem. Nesta caracterização aparecem relacionados com a arte da enfermagem outros padrões de conhecimento como o ético e o pessoal.

Nesse contexto, Silva, et al., (2005) e Fernandes, et al., (2011) defendem que a visão cartesiana que sobrevaloriza a ciência como soberana se tornou o único caminho de conhecimento da área médica, aproximando o saber técnico à enfermagem, enquanto valor científico em detrimento ao saber humano, que é representado pela arte, assim, a visão cartesiana afasta o agir reflexivo e criativo da profissão. A arte do cuidar é direcionada de acordo com cada singularidade, um conjunto de símbolos e valores que revelam uma linguagem íntima, conferindo ao cuidado uma dimensão humanística e dotada dos princípios holísticos, portanto, a articulação entre ciência e arte torna-se necessária.

\section{Atributos pessoais para ser um bom enfermeiro}

As respostas ao questionamento: "Em sua opinião quais as características necessárias para ser um bom enfermeiro?" são diversificadas, entretanto, os valores nightingaleanos e religiosos aparecem em grande parte dos discursos:

“Delicadeza, paciência, dedicação”. (Orestes)

"[...] ser sencivel as necessidade do outro compriencivo, pacienssoso [...]". (Poseidon)

“Calma, educação, paciência, amor”. (Atenas)

“O amor ao próximo, a paciência [...]”. (Eros)

"Paciência, simpático, gentil”. (Afrodite) 
"[...] ser apaixonado pelo que faz; ter respeito e tempo para dedicar-se aos estudos e à profissão”. (Perseu)

“[...] educado, paciente, extrovertido, alegre”. (Cromos)

“Liderança, pensamento critico, altruísmo [...]”. (Panaceia)

“Empenho, dedicação e estudo [...]”. (Dionísio)

“[...] respeitoso, ético, idealista, comunicativo e prestativo”. (Asclépio)

"[...] honesto, dedicado [...] amar a profissão que escolheu [...]”. (Pegaso)

As falas dos sujeitos apresentam de forma objetiva e explícita atributos femininos que em suas concepções são fundamentais para ser um bom cuidador, são características que o imaginário social não concebe para figura masculina, que deve andar na contramão da delicadeza e da paciência, pois, ser homem do ponto de vista social é ser agressivo, ser forte, insensível, bruto, desajeitado. Logo essas características fazem referência ao sexo feminino, por conta da elaboração cultural de gênero que situa a mulher como delicada, sensível, dócil, atenciosa (PEREIRA, 2008).

Paciência, docilidade, dedicação, sensibilidade, amor, delicadeza e serviço são algumas das características presentes no discurso dos sujeitos. Para Panaceia um bom enfermeiro deve ser altruísta; altruísmo pode ser definido como "amor ao próximo, desprendimento, abnegação; doutrina que considera como fim da conduta humana o interesse do próximo, e que se resume nos imperativos: 'Viva para outrem'; 'Ama o próximo como a ti mesmo"” (FERREIRA, 2009). Vejamos que essa é uma concepção cristã que vigora até os dias de hoje, herança das companhias e ordens religiosas que por muito tempo realizaram o cuidado pelo mundo por meio de obras de assistência social; dentre elas destacam-se a Ordem dos Franciscanos e as Irmãs de Caridade, nessa última as irmãs se reuniam para receber o Espírito de Deus e a missão de cuidar do outro, pois assistir o doente era cumprir os desígnios de Deus (KAWAMOTO, 1997; SOUZA JÚNIOR, et al., 2003; SANTOS, 2005).

Pegaso reforça o valor nightingaleano de boa índole, a honestidade refere-se à integridade, à dignidade, um atributo que Florence esperava de suas alunas. Reforça-se que, essas concepções são construções culturais propagadas de modo explícito ou subjetivo pela História da Enfermagem ao longo dos tempos. Entendemos que alguns desses atributos são essenciais para a prática de enfermagem e estão presentes de forma intrínseca nos conceitos atuais de humanização do cuidado e holismo, o que nos preocupa são as repercussões negativas 
desses valores, idealizando uma imagem de enfermagem que não condiz com a prática profissional, com a realidade do enfermeiro.

Em uma reflexão sobre o conteúdo das falas dessa categoria, percebemos que há uma diferença de valores entre o segundo e o último período, no discurso do primeiro grupo pouco se destacam competências técnico científicas, as falas refletem um discurso religioso e nightingaleano. Entretanto, no segundo grupo esses valores são apresentados de maneira tímida, respaldados por um discurso que vende a enfermagem como ciência e que reforça as competências gerenciais, assistenciais e científicas do enfermeiro.

Assim, podemos dizer que o fator contribuinte para essa mudança seja a vivência do aluno ao longo das disciplinas, especialmente aquelas que provocam discussões teóricas, como por exemplo, a Sociologia, Antropologia, Ética e a Filosofia, assim, o ensino por meio da articulação teórico prática seria o fator preponderante dessa mudança de concepção.

\section{Enfermagem: ciência do cuidado}

De acordo com Lima (2005, p.27), “a enfermagem é uma ciência humana de pessoas e experiências voltada ao cuidado dos seres humanos, cujo campo de conhecimento, fundamentações e práticas abrange desde o estado de saúde até os estados de doença”. Portanto, a essência da enfermagem é o cuidar, e para tanto, necessita de um conhecimento integral e global da pessoa. Nesse sentido, de acordo com Souza, et al., (2005), o cuidado significa desvelo, solicitude, zelo, atenção, sendo concretizado no contexto da vida em sociedade.

A partir dessa premissa, a presente categoria pretende analisar de que forma os sujeitos concebem a Enfermagem enquanto ciência e cuidado. Entendemos que refletir sobre o cuidado é partir do princípio de que existem diferentes expressões do que é cuidar. A respeito dessas variadas concepções, os sujeitos revelam:

\footnotetext{
"A enfermagem desde sempre para mim foi a concepção do cuidado e contato com o próximo de maneira que os meus serviços possam fazer a diferença, ajudando o paciente em momentos delicados de sua vida [...]”. (Eros) "A concepção de passar cuidado para os que não tem, ou seja ser um cuidador". (Cronos)

“O cuidar do ser humano e suas necessidades". (Panaceia)

"Enfermagem é o ato de cuidar ser enfermeiro é ser uma pessoa que tem a consciência e a preocupação com o bem estar do individuo como um todo". (Hermes)
} 
"Enfermagem tem o que todo ser humano precisa, de humanização, e cuidado acima de tudo de qualidade, como forma de manter a sociedade com saúde em todas as suas definições”. (Eros)

"Enfermagem é cuidar. Ser enfermeiro é prestar cuidado, gerenciar o cuidado, se colocar a disposição do outro”. (Medusa)

Partindo do pressuposto de que diferentes indivíduos expressam diferentes maneiras de cuidar, entendemos que o conceito de cuidado enquanto essência da Enfermagem recebe interferência de outros conceitos, que são construídos e desconstruídos ao longo da graduação e da história de vida de cada sujeito.

A esse respeito, uma maneira de se perceber o cuidado é concebê-lo enquanto ciência. $\mathrm{Na}$ década de 60 na América do Norte iniciou-se uma grande busca no intuito de elaborar modelos conceituais e teorias de enfermagem, a fim de desenvolver um corpo de conhecimento específico, promovendo uma identidade profissional. As teorias proporcionaram um campo de saber especifico da enfermagem, sendo um forte divisor entre a enfermagem empírica e a enfermagem científica (ANDRADE, 2007; OLIVEIRA; PAULA; FREITAS, 2007).

Outro avanço importante para consolidação da enfermagem enquanto ciência ocorre no Brasil a partir da década de 80 , onde foi verificada uma necessidade de definir os currículos mínimos dos cursos de graduação, no sentido de traçar caminhos para a formação superior brasileira. Neste contexto as Diretrizes Curriculares dos Cursos de Graduação em Saúde são criadas visando atender às exigências da nova Lei de Diretrizes e Bases da Educação Nacional (LDB). Em 7 de dezembro de 2001, foi sancionada a Resolução $n^{\circ} 03$ de 7/11/2001 instituindo as Diretrizes Curriculares Nacionais do Curso de Graduação em Enfermagem (DCN/ENF) (FERNANDES et al., 2005; ITO et al., 2006; CORBELLINI et al., 2010; SILVA; SOUSA; FREITAS, 2011).

As DCNs do Curso de Graduação em Enfermagem apontam para uma formação de profissionais que ultrapassem o domínio teórico-prático exigido pelo mercado de trabalho, buscando torná-los agentes de mudança (ITO et al., 2006; SILVA; SOUSA; FREITAS, 2011). Dessa forma as novas DCN/ENF tem como objetivo formar enfermeiros qualificados para o exercício da profissão com as seguintes competências e habilidades: “atenção à saúde, tomada de decisões, comunicação, liderança, administração e gerenciamento e educação permanente" (ITO, et al., 2006, p. 572). “As DCNs procuram aproximar o cuidado individual, na perspectiva da saúde coletiva, com vistas à integralidade da atenção em saúde" (CORBELLINI, et al., 2010, p. 556). 
No presente estudo, dentre os discursos de alguns discentes foi possível identificar a concepção de Enfermagem como ciência, que vai de encontro às novas DCN/ENF:

"A enfermagem é uma área fundamentada, embasada em evidências, um saber teórico prático, que usa o atendimento do ser humano em suas necessidades humanas básicas de forma integral. Ser enfermeiro é ser compromissado com a vida, ser agente atuante e modificador do ambiente em que está inserido". (Hércules)

Hércules demonstra em seu discurso que além da necessidade do embasamento cientifico, o profissional enfermeiro atua como agente de mudança, intervindo com sua prática baseada em evidências no ambiente que está inserido. Panaceia e Dionísio possuem uma visão de que o enfermeiro deve ser um profissional generalista, capaz de intervir nas mais diferentes situações de saúde e em todas as fases do desenvolvimento humano:

"Enfermagem é a profissão que cuida do ser humano em todas as fases da vida e, em suas complexidades, necessidades, utilizando o método cientifico de modo reflexivo e humano. Enfermeiro é o profissional que cuida, mantem, previne e recupera a saúde". (Panaceia)

"Significa uma profissão de forte embasamento cientifico com visão generalista apto a prestar assistência ao individuo em qualquer fase de sua vida [...]". (Dionísio)

Panaceia traz uma definição de enfermagem que se aproxima da fala das teoristas, o que atribui a esse discurso um caráter científico. O conteúdo desse discurso nos leva a refletir sobre a importância da profissão e do uso de ferramentas/conceitos como a humanização, holismo, promoção e prevenção, e a integralidade do cuidado.

As falas de Asclépio e Apolo apontam para a formação de enfermeiros aptos a atuarem no atual contexto de saúde, capazes de desenvolverem competências e habilidades necessárias: tomada de decisão, comunicação, liderança, administração e gerenciamento. Asclépio ainda em seu discurso remete a necessidade do cuidado integral, afastando-se do cuidado empírico, e voltando-se para o saber específico da enfermagem que é o cuidado sistematizado baseado em conhecimentos científicos e teorias de enfermagem, dando a estes discursos um caráter cientifico:

"Enfermagem é a realização de cuidados integrais, planejados e embasados cientificamente. Ser enfermeiro é ser planejador, gerente, líder e ser (ter que ser) dotado de conhecimento cientifico adquirido, é ser organizado e sistemático, ágil, e capacitado para lidar com equipes e com pacientes". (Asclépio) 
"Enfermagem é a gerencia do cuidado, envolve todas as ações (administrativas e assistenciais)[...]. Enfermeiro representa o profissional que exerce o cuidado e gerencia este cuidado”. (Apolo)

Em relação às características necessárias para ser um bom enfermeiro, foi possível identificar nos discurso de Asclépio, Apolo e Medusa o conhecimento do perfil exigido nas novas DCN/ENF:

"Criativo, organizado, gerente, sistemático, cuidador, líder, compreensivo, ter boa relação interpessoal, buscar acrescentar seus conhecimentos, respeitoso, ético, idealista, comunicativo e prestativo". (Asclépio)

"Liderança, conhecimento técnico cientifico, trabalho em equipe, responsabilidade, ética”. (Apolo)

"Conhecimento científico, liderança, saber usar os instrumentos básicos como: comunicação, observação. Saber interagir com os demais profissionais de saúde. Agir em todas as situações com ética, respeitando os direitos e privacidade do paciente”. (Medusa)

É possível perceber nos discurso de ambos a importância da formação generalista do profissional enfermeiro com base nos princípios científicos, e desenvolver ao longo de sua formação competências e habilidades necessárias para o atendimento à saúde, tomada de decisão, comunicação, liderança e gerenciamento.

\section{CONSIDERAÇÕES FINAIS}

Ao refletir sobre o conteúdo das falas dos sujeitos não tivemos a intenção de fazer julgamentos de valores, pois, entendemos que inúmeros fenômenos estão envolvidos no processo de conceber uma ideia, e, ao julgar essas concepções estaríamos ignorando as particularidades de cada indivíduo.

Nesse sentido, entendemos que somos responsáveis e autores de nossa própria história, acreditamos que os sujeitos estão em constante aprendizado com o meio que o cerca, influenciados pelos elementos culturais, sociais e históricos e por diversos fenômenos que são específicos de cada um. Logo o estudante de enfermagem aprende conceitos palpáveis ou subjetivos da história de sua profissão, através de sua relação com o mundo, com seu objeto de estudo; o mesmo reconstrói este mundo, transforma essa visão, essa ideia concebida e aprendida, através da interação com o meio. 
Enfatizamos que refletir sobre o cuidado é refletir sobre a natureza humana, portanto, ao imergir no imaginário dos sujeitos, o pesquisador se defronta com a subjetividade, que como explicitado anteriormente refere à singularidade de cada ser social. Emergiram das falas dos sujeitos algumas concepções que se referem à enfermagem enquanto arte, vocação, doação, cuidado à pessoa humana e ciência. Ao comparar as concepções entre o segundo e o décimo período, observamos que os alunos que representam os egressos do curso, possuem uma visão mais ampla da enfermagem, abarcada de valores e atributos científicos, herança do contínuo processo ensino aprendizagem que contribui para construção e desconstrução de ideias e conceitos. Ao nos propormos analisar as diferentes concepções não tínhamos a intenção de promover uma dicotomia entre cuidado e ciência, acreditamos, que o cuidado faz parte da história da humanidade, seja ele empírico ou científico, são apenas diferentes olhares sobre o mesmo fenômeno.

Cabe ressaltar a importância de estudos que busquem conhecer as concepções de acadêmicos de enfermagem sobre sua profissão e visão de mundo, neste sentido, pesquisas poderão contribuir para análises mais significativas sobre o processo de formação de profissionais de enfermagem, acarretando em possíveis reformulações no processo ensino aprendizagem, na reprodução de concepções que refletem à construção da identidade profissional dos sujeitos.

\section{REFERÊNCIAS}

ANDRADE, A. C. A enfermagem não é mais uma profissão submissa. Rev. Bras. Enferm., Brasília, v. 60, n. 16, p. 96-8, jan/fev. 2007.

BAGGIO, M. A. et al. (In) visibilidade do cuidado e da profissão de enfermagem no espaço de relações. Acta Paul Enferm., São Paulo, v. 23, n. 6, p. 745-50, maio/jun. 2010.

BARDIN, L.. Análise de conteúdo. São Paulo: Edições 70, 2011. 223 p.

BRANQUINHO, N.C.S.S. et al. Egressos de Enfermagem: uma revisão sistemática da literatura. In: $63^{a}$ Reunião Anual da SBPC, Julho, 2011. Anais da 63 $^{\mathbf{a}}$ Reunião Anual da SBPC; Goiânia-GO, Brasil. Disponível em: <http://www.sbpcnet.org.br/livro/63ra/conpeex/mestrado/trabalhos-mestrado/mestrado-naylacecilia.pdf> Acesso em: 10 de dezembro de 2012. 
BRASIL. Ministério da Educação. Conselho Nacional de Educação. Câmara de educação superior. Resolução CNE/CES no 3 de 7/11/2001: Diretrizes Curriculares Nacionais do Curso de Graduação em Enfermagem, Brasília, 2001.

BRASIL. Ministério da Saúde. Conselho Nacional de Saúde. Resolução Nº 196/96; Diretrizes e normas regulamentadoras de pesquisa envolvendo seres humanos. Brasília, 1996.

BRASIL. Ministério da Saúde. Ministério da Educação. Programa Nacional de Reorientação da Formação Profissional em Saúde - Pró-Saúde: objetivos, implementação e desenvolvimento potencial. Brasília, 86 p. 2007.

BRITO, A.M.R. Representações sociais de discentes de Enfermagem sobre ser enfermeiro. Belo Horizonte, 2008. 151 f. Dissertação (Mestrado) - Escola de Enfermagem, Universidade Federal de Minas Gerais, Belo Horizonte, 2008.

CARRIJO, C.I.S. et al. A empregabilidade de egressos de um curso de graduação em enfermagem. Rev. Enferm. UERJ, Rio de Janeiro, v.15, n.3, p. 356-63, jul/set, 2007.

CESTARI, M.E. Padrões de conhecimento da enfermagem e suas implicações no ensino. Rev Gaúcha Enferm., Porto Alegre (RS), v. 24, n.1, p. 34-42, Abr. 2003.

COLPO, J.C. et al. A imagem corporal da enfermeira como objeto sexual na mídia: um assédio a profissão. Cogitare Enferm., v.11, n.1, p. 67-72, jan/abr. 2006.

CORBELLINI, V.L. et al. Nexos e desafios na formação profissional do enfermeiro Rev Bras Enferm., Brasília, v.63, n.4, p. 555-60, jul/ago. 2010.

ERDMANN, A.L. et al. A visibilidade da profissão de enfermeiro: reconhecendo conquistas e lacunas. Rev Bras Enferm., Brasília, v. 62, n. 4, p. 637-43, jul/ago. 2009.

FERNANDES, G.C.M. et al. As expressões da arte em enfermagem no ensino e no cuidado em saúde: estudo bibliométrico. Texto Contexto Enferm., Florianópolis, v. 20, n. 1, p. 167-74, Jan/Mar. 2011.

FERNANDES, J. D. et al. Diretrizes curriculares e estratégias para implantação de uma nova proposta pedagógica. Rev Esc Enferm , USP., v. 39, n. 4, p. 443-9, 2005. 
FERREIRA, A. B. H. Novo dicionário Aurélio da língua portuguesa. $4^{\mathrm{a}}$ ed. Curitiba: Ed. Positivo, 2009. 2120 p.

FREIRE, P.. Pedagogia do oprimido. $17^{\mathrm{a}}$ ed. Rio de Janeiro: Paz e Terra, 1987.

GABRIELLI, J.M.W. Formação do enfermeiro: buracos negros e pontos de luz. Ribeirão Preto. 182 f. Tese (Doutorado) - Escola de Enfermagem, Universidade São Paulo; 2004.

GALLEGUILLOS, T.G.B. et al. A gênese e o desenvolvimento histórico do ensino de enfermagem no Brasil. Rev Esc Enf USP, v.35, n. 1,p. 80-7, mar. 2001.

GENTIL, R.C. O enfermeiro não faz marketing pessoal: a história explica por quê?. Rev. Bras. Enferm., Brasília, v. 62 n. 6, p. 916-8, nov/dez. 2009.

GEOVANINI, T. et al. História da enfermagem: versões e interpretações. 3.ed. Rio de Janeiro: Revinter, 2010.

GERMANO, R.M. Educação e ideologia da Enfermagem no Brasil. $3^{\text {a }}$ Ed. São Paulo: Cortez, 1993.

HADDAD, A. E. et al (Org.). A trajetória dos cursos de graduação na área da saúde: 19912004. Brasília: INEP- Instituto Nacional de Estudos e Pesquisas Educacionais Anísio Teixeira; Ministério da Educação, 2006. 531 p.

ITO, E. E. et al. O ensino de enfermagem e as diretrizes curriculares nacionais: utopia $\mathrm{x}$ realidade. Rev Esc Enferm, USP. v. 40, n.4, p. 570-5, 2006.

KAWAMOTO, E.E. Fundamentos de enfermagem. $2^{\mathrm{a}}$ Ed. rev. e atual. - São Paulo: EPU, 1997.

KEMMER, L.F. et al. Como escolher o que não se conhece? Um estudo da imagem do enfermeiro por alunos do ensino médio. Acta Paul de Enferm., São Paulo, v. 20, n.2, p. 125$130,2007$.

LANZA, L.B. Enfermeiros-homens: uma nova identidade em construção. Tese (Doutorado). Pontífica Universidade Católica de São Paulo, 2006. 184 p.

LIMA, M.J. O que é enfermagem. Coleção primeiros passos, São Paulo: Brasiliense, 2005. $125 \mathrm{p}$. 
OLIVEIRA, M. L.; PAULA, T. R.; FREITAS, J. B. Evolução da assistência de enfermagem. ConScientiae Saúde, São Paulo, v. 6, n. 1, p. 127-136, 2007.

PAIXÃO, W. História da enfermagem. 5. ed. rev. e atual. Rio de Janeiro: Júlio C. Reis Livraria, 1979.

PEREIRA, P.F. Homens na enfermagem: atravessamentos de gênero na escolha, formação e exercício profissional. Dissertação de Mestrado - Escola de Enfermagem da UFRGS, Porto Alegre, 2008. 104 p.

RODRIGUES, R.M. Enfermagem compreendida como vocação e sua relação com as atitudes dos enfermeiros frente às condições de trabalho. Rev Latino-am Enfermagem, v. 9, n. 6, p. 76-82, 2001.

ROSA, R.B. et al. Concepções de acadêmicos de enfermagem sobre o que é ser enfermeiro. Acta Paul Enferm, v. 18, n. 2, p. 125-30, 2005.

SANTOS, A.M.R. et al. A atuação da irmã de caridade Abrahíde Alvarenga no Piauí: uma história a ser contada. Texto Contexto Enferm, Florianópolis, v. 14, n.4, p. 551-6; out/dez. 2005 .

SILVA, L.W.S. et al. Arte na enfermagem: iniciando um diálogo reflexivo. Texto Contexto Enferm; v. 14, n.1, p. 120-3, Jan/Mar. 2005.

SILVA, M. J.; SOUSA, E. M.; FREITAS, C. L. Formação em enfermagem: interface entre as diretrizes curriculares e os conteúdos de atenção básica. Rev Bras Enferm. v. 64, n.2, p. 315$21,2011$.

SOUZA JUNIOR, J.G.C. et al. Como será o amanhã? Responda quem puder! Perspectivas de enfermeirandos quanto ao seu futuro profissional. Rev Bras Enferm, v. 56, n. 4, p. 453-458, 2003.

WAINBERG, S. Experiências e vivências de auxiliares de enfermagem do sexo masculino no exercício de uma profissão majoritariamente feminina. Dissertação (Mestrado), Instituto de Psicologia, UFRGS, Porto Alegre, 2004. 62 p. 